Revista Universo Contábil, ISSN 1809-3337

Blumenau, v. 12, n. 2, p. 17-136, abr./jun., 2016

doi:10.4270/ruc.2016217

Disponível em www.furb.br/universocontabil

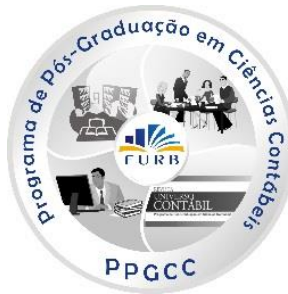

\title{
CUSTO DO CAPITAL PRÓPRIO EM EMPRESAS BRASILEIRAS DO SETOR SUCROENERGÉTICO: UM ESTUDO CONSIDERANDO A ADOÇÃO DAS NORMAS INTERNACIONAIS DE CONTABILIDADE'
}

\section{COST OF EQUITY IN BRAZILIAN COMPANIES OF THE SUGARCANE INDUSTRY: A STUDY CONSIDERING THE ADOPTION OF INTERNATIONAL FINANCIAL REPORTING STANDARDS}

\section{COSTO DE CAPITAL PROPRIO EN EMPRESAS BRASILEÑAS DEL SECTOR SUCROENERGETICO: UN ESTUDIO CONSIDERANDO LA ADOPCIÓN DE LAS NORMAS INTERNACIONALES DE CONTABILIDAD}

Aviner Augusto Silva Manoel

Mestre e Doutorando do Programa de Controladoria e Contabilidade pela Faculdade de Economia, Administração e Contabilidade de Ribeirão Preto da Universidade de São Paulo (FEA-RP/USP) Endereço: Av. dos Bandeirantes, 3900 - FEA-RP CEP: 14040-905 - Ribeirão Preto - SP - Brasil E-mail: aviner@usp.br Telefone: +55 (16) 99229-9405

João Paulo Augusto Eça Graduando em Administração pela Universidade Estadual de Montes Claros (UNIMONTES) Endereço: Av. Rui Barbosa, 126 - Vila Mauriceia CEP: 39401-089 - Montes Claros - MG - Brasil E-mail: joaopauloeca@gmail.com Telefone: +55 (38) 3229-8255

Marcelo Botelho da Costa Moraes

Professor Doutor do Departamento de Contabilidade da Faculdade de Economia, Administração e Contabilidade de Ribeirão Preto da Universidade de São Paulo (FEA-RP/USP) Endereço: Av. dos Bandeirantes, 3900 - FEA-RP Bloco C2 sala 39 CEP: 14040-905 - Ribeirão Preto - SP - Brasil E-mail mbotelho@usp.br Telefone: +55 (16) 3315-9015

\section{RESUMO}

Seguindo a tendência mundial, no Brasil, a partir de 2008, teve início o processo gradual de adoção às Normas Internacionais de Contabilidade (International Financial Reporting Standards - IFRS) da International Accounting Standards Board (IASB). Sendo assim, o presente estudo objetiva analisar se a adoção das IFRS proporcionou redução do custo de

\footnotetext{
${ }^{1}$ Artigo recebido em 13.01.2016. Revisado por pares em 29.04.2016. Reformulado em 19.07.2016. Recomendado para publicação em 25.07.2015 por Paulo Roberto da Cunha. Publicado em 26.08.2016. Organização responsável pelo periódico: FURB.
} 
capital próprio nas usinas e destilarias do setor sucroenergético brasileiro, um setor com alta concentração acionária e majoritariamente composto por empresas de capital fechado. Para mensurar o custo do capital próprio, utilizou-se do modelo CAPM (Capital Asset Princing Model) por benchmark. A análise dos dados se deu por meio do método de regressão com dados em painel entre 1998-2014. Os resultados obtidos apontam que o custo de capital pode ser explicado negativamente pelas variáveis "ROE" e "Tamanho da Empresa" e positivamente pela "Estrutura de capital". A variável "IFRS", por outro lado, não se mostrou estatisticamente significativa, denotando, dessa forma, que a adoção das IFRS não afetou o custo de capital próprio das organizações estudadas.

Palavras-chave: CAPM, IFRS, Agronegócio

\section{ABSTRACT}

Following the global trend, in 2008 Brazil began the gradual process of adopting the International Financial Reporting Standards (IFRS) of the International Accounting Standards Board (IASB). Thus, the present study aims to examine whether the adoption of IFRS provided a reduction of the cost of equity in the mills and distilleries of the Brazilian sugarcane industry, a sector with high ownership concentration and mainly composed of privately held companies. To measure the cost of equity, we used the CAPM (Capital Asset Pricing Model) by benchmark. Data analysis was done through regression method with panel data for the period between 1998-2014. The results indicate that the cost of equity can be explained negatively by the variables "ROE" and "Company Size" and positively by the "Capital Structure". The variable "IFRS", on the other hand, was not statistically significant, denoting thus that the adoption of IFRS did not affect the cost of equity of the organizations studied.

Keywords: CAPM, IFRS, Agribusiness.

\section{RESUMEN}

Siguiendo la tendencia mundial, en el Brasil, comenzó a partir del año 2008, el proceso gradual de adopción de las Normas Internacionales de Contabilidad - NIC, en inglés (International Financial Reporting Standards - IFRS) del International Accounting Standards Board (IASB). Así, este estudio tiene como objetivo analizar si la adopción de las NIC proporciona reducción del costo de capital propio en plantas y destilerías de azúcar en el sector sucroenergetico brasileño, un sector de concentración accionario alto, y, compuesto en su mayoría por empresas de capital cerrado. Para medir el costo de capital propio de las empresas, se utilizó el modelo CAPM (Capital Asset Pricing Model) como referencia. El análisis de datos se realizó por medio del método de regresión con datos en panel entre los años de 1998 al 2014. Los resultados del análisis indican que el costo de capital propio de las empresas estudiadas puede explicarse negativamente por las variables "ROE" y "Tamaño de Empresa" y positivamente por la variable "Estructura de Capital". La variable "IFRS", por otro lado, no fue estadísticamente significativa, reflejando que la adopción de las NIC no afectó el costo de capital proprio de las organizaciones estudiadas.

Palabras clave: CAPM, IFRS, Agroindustria.

\section{INTRODUÇÃO}

A maior abertura econômica brasileira ao mercado internacional nos últimos anos e o acréscimo no número de transações entre os países resultou na necessidade da padronização 
das normas contábeis devido à diversidade e especificidades contábeis de cada local. Fatores estes que acarretavam em custos desnecessários, em informações assimétricas e em menor poder assertivo de decisão.

Sendo assim, a partir do ano de 2008, em decorrência da Lei 11.638/2007, o Brasil seguiu a tendência mundial e começou a adotar gradualmente as Normas Internacionais de Contabilidade (International Financial Reporting Standards - IFRS), que são emitidas pelo International Accounting Standards Board (IASB) (ANTUNES et al., 2012). Sua obrigatoriedade plena ocorreu apenas no ano de 2010, com a adoção do conjunto completo de normas IFRS, para as demonstrações financeiras consolidadas, conforme as normas emitidas pelo Comitê de Pronunciamentos Contábeis - CPC no Brasil, de todo tipo de sociedade (SANTOS; PONTE; MAPURUNGA, 2014).

Anteriormente, o Parlamento Europeu já havia aprovado em 2002 uma resolução exigindo que todas as entidades constantes nas bolsas dos Estados-Membros europeus adotassem as IFRS na preparação de suas demonstrações financeiras a partir de 2005 (ARMSTRONG et al., 2010; LOURENÇO; BRANCO, 2015a).

Uma queixa comum anterior à adesão às IFRS na Europa era de que as diferenças nos modelos contábeis tornavam a vida do analista mais complicada, como por exemplo, no caso dele tentar estimar os possíveis ganhos futuros de uma organização (BROWN, 2013). Nesse sentido, o uso de um único modelo de normas contábeis internacional foi instaurado no intuito de melhorar a comparabilidade, a qualidade e a confiabilidade das informações divulgadas para os seus usuários, além de reduzir os custos de preparação das demonstrações financeiras e proporcionar maior tempestividade e relevância contábil (ANTUNES et al., 2012; ARMSTRONG et al., 2010).

Atualmente, segundo informações da Fundação IFRS (2015), cerca de 138 países adotam o padrão internacional de contabilidade, de modo que este número vem crescendo ao longo dos anos. Dentre as economias consideradas mais desenvolvidas do planeta, somente os EUA, Índia e Japão que até o prezado momento não aderiram às IFRS ou normas substancialmente convergentes (LOURENÇO; BRANCO, 2015a). Mesmo assim, destaca-se o esforço de convergência entre as normas internacionais IFRS e as normas emitidas pelo FASB (Financial Accounting Standards Board), órgão normatizador norte-americano.

A mudança recente de grande parte dos países para as normas IFRS, segundo Daske et al. (2008), é uma das questões regulamentares mais relevantes da história da contabilidade. Para os autores, as lições e os méritos dessa mudança ainda são tema de debates, e para Lee, Walker e Christensen (2010), as opiniões entre acadêmicos e profissionais do mundo inteiro ainda são divididas em relação aos potenciais benefícios econômicos da adoção obrigatória.

Em função da maior qualidade da informação e melhora na sua comparabilidade, espera-se que, em decorrência da convergência do Brasil às normas da IFRS, os usuários dessas informações sejam capazes de monitorar de forma mais eficaz o desempenho gerencial das organizações, o que, portanto, levá-los-ia a exigir um prêmio mais baixo pelo risco de mercado (LEE; WALKER; CHRISTENSEN, 2010).

Assim, a crença de que a maior divulgação de informações contábeis pelas empresas deva reduzir o seu custo de capital próprio, segundo Castillo-Merino, Menéndez-Plans e Orgaz-Guerrero (2014), tem levado muitos países a adotar as IFRS.

Para Li (2010), há pelo menos duas razões para obrigatoriedade de adesão das normas reduzirem o custo de capital próprio. Primeiro, adotar as IFRS requer uma maior divulgação financeira do que quando da vigência das respectivas normas locais de cada país, portanto, espera-se que com o aumento do disclosure haja uma redução do custo de capital próprio. Um conjunto de normas contábeis uniformes entre os diversos países, por sua vez, entraria como o segundo motivo suscetível de melhorar a comparabilidade da informação entre as empresas, e que, por consequência, reduziria também o custo de capital. 
Porém, no que diz respeito ao caso brasileiro, os resultados encontrados podem divergir dos obtidos em trabalhos que analisam países europeus, por exemplo, podem não ser os mesmos, devido a diversos motivos. Gatsios et al. (2015) elencam alguns fatores para tal: i) a adesão das IFRS ocorreu no período da crise mundial do subprime de 2008; ii) diferenças mais acentuadas entre o antigo modelo contábil e o novo padrão IFRS; iii) influência da contabilidade fiscal na elaboração dos relatórios contábeis; iv) mercado de capitais brasileiro menos desenvolvido quando comparado aos grandes centros; v) menor poder de enforcement por parte das instituições.

Dessa forma, os efeitos encontrados a partir da adoção das normas em países europeus podem ser diferentes, por exemplo, no caso brasileiro, em função das diferenças econômicas, institucionais e também temporais, decorrentes da adoção brasileira mais recente. De forma complementar, Silva e Nardi (2014) citam que o grau de beneficiamento dos usuários com a adoção do Brasil às normas IFRS não é algo consolidado pela literatura. Considerando que a convergência brasileira às normas ocorreu em duas etapas e não há relatos de casos parecidos, entende-se que um estudo que investigue se as consequências identificadas em outros países, por exemplo, também se aplicam ao Brasil seja importante.

Deste modo, este trabalho contribui para a literatura na tentativa de elucidar melhor uma possível consequência da adoção das normas IFRS, conforme previsto na literatura especializada: redução do custo de capital próprio. Porém, o estudo apresenta sua contribuição ao tratar de um contex to diferente do reportado na literatura prévia, ao considerar um setor em que as relações de incentivos não necessariamente apontam no objetivo da empresa em reduzir seu custo do capital próprio, uma vez que se trata de um setor majoritariamente de capital fechado.

A escolha do setor sucroenergético justifica-se pela relevância econômica e social do mesmo para a economia brasileira. Atualmente, segundo dados do Jornalcana (2015) correspondentes à safra 2014/2015, o setor com suas 423 usinas e destilarias gerou 4,5 milhões de empregos diretos e indiretos, movimentou cerca de 70 bilhões de reais ao ano entre as atividades de produção de açúcar, bioeletricidade, cana e etanol, representando, dessa forma, 1,3\% do PIB brasileiro.

Ademais, Soares et al. (2011) elencam que ao longo dos anos o setor sucroenergético brasileiro vem se mostrando atrativo ao investidor estrangeiro, sobretudo por causa da considerável demanda internacional por álcool carburante e à competitividade do produto nacional.

$\mathrm{Na}$ última década, por exemplo, o setor apresentou crescente desenvolvimento, especialmente em decorrência do lançamento dos automóveis com motores flex fuel, capazes de funcionar com etanol hidratado, gasolina, ou qualquer mistura dos dois combustíveis, fato este que ocorreu no ano de 2003. De forma complementar, cita-se também o uso dos resíduos oriundos do processamento da cana, tais como, o bagaço na produção de bioeletricidade, ração animal e celulose que também auxiliaram no desenvolvimento do setor (UNICA, 2015).

Todavia, nos últimos anos, segundo Neves et al. (2014) e Santos, Garcia e Shikida (2015), o setor enfrenta uma de suas piores crises, atingido por fatores climáticos, como pela falta de chuvas, especialmente em 2014 e início de 2015, assim como devido às políticas públicas de controle no preço da gasolina do governo e à queda do preço do açúcar no mercado internacional. Dessa forma, a conjuntura não é mais de crescimento. O setor vem se ressentindo de margens estreitas ou negativas, aumento do endividamento e estagnação dos investimentos. E um dos efeitos observados e apontados por Neves et al. (2014) em seu trabalho é o fechamento de usinas e destilarias e aumento no número de pedidos de recuperação judicial, que no intervalo de janeiro e outubro de 2014 afetou 62 grupos econômicos e, por consequência, aumentou o desemprego (NEVES et al., 2014). 
Se analisadas as alterações proporcionadas pelas IFRS sobre o setor, merecem destaque as normas IAS 39 e IFRS 7, referentes aos Instrumentos Financeiros (no Brasil correspondentes as normas CPC 39 e 40) por causa dos efeitos do reconhecimento à valor justo dos instrumentos financeiros, especialmente nas operações relacionadas aos contratos e derivativos de commodities agropecuárias, bem como os efeitos da norma IAS 41 (CPC 29) relativas a Ativo Biológico e Produto Agrícola. Assim, a adoção destas normas no setor, apresentam grandes diferenças em relação aos demais setores da economia nacional e justificam um estudo a parte.

Outra característica importante que justifica o estudo específico neste setor é a predominância de empresas de capital fechado, em que existe a discricionariedade na adoção das IFRS. Dessa forma, a presente pesquisa também contribui para um maior conhecimento sobre este processo.

Sendo assim, a adoção do padrão IFRS contribui para a redução do custo de capital próprio das empresas do setor sucroenergético no Brasil?

Para tanto, o objetivo deste trabalho é verificar se adoção das normas IFRS reduziu o custo de capital próprio das empresas do setor sucroenergético como indicado por alguns estudos nacionais e internacionais.

Dessa maneira, foi observado se houveram mudanças significativas no custo de capital das empresas do setor sucroenergético durante a mudança e após a adoção das normas IFRS.

\section{REFERENCIAL TEÓRICO}

\subsection{Adoção do padrão IFRS}

O International Accounting Standards Board (IASB), de acordo com Lourenço e Branco (2015b), é uma organização privada de âmbito internacional, criada em 1973, que tem como objetivo o estudo, preparo e a emissão de normas de padrões internacionais de contabilidade. Além disso, para Barth, Landsman e Lang (2008), figuram-se como meta do IASB o desenvolvimento de normas internacionais de informações financeiras altamente qualificadas.

Para preparação das demonstrações financeiras foi emitido pelo IASB um conjunto de normas, a saber: i) 41 International Accounting Standards (IAS) e ii) 13 International Financial Reporting Standards (IFRS) (LOURENÇO; BRANCO, 2015b). As normas adotadas pelo IASB se fizeram necessárias para que as medições contábeis possam tornar-se cada vez mais fidedignas, ou seja, refletindo a situação econômica e o desempenho das empresas de uma melhor maneira (BARTH; LANDSMAN; LANG, 2008).

$\mathrm{O}$ ano de 2005 representa um marco importante para a contabilidade, pois foi neste ano que se tornou obrigatória a adoção das IFRS na União Europeia (UE) e na Austrália. Anteriormente a isso, por exemplo, a maioria das empresas europeias aplicava normas de contabilidade domésticas (ARMSTRONG et al., 2010). Dessa forma, a União Europeia, determinou que todas as empresas listadas nas bolsas dos Estados-Membros europeus adotassem as IFRS em 2005, com objetivo de aumentar a eficiência do mercado de capitais, e assim, proteger os interesses dos investidores (CASTILLO-MERINO; MENÉNDEZ-PLANS; ORGAZ-GUERRERO, 2014).

Para Brown (2013), há diversas razões para que os países as adotem. Assim, para alguns, a demanda pelas IFRS é impulsionada pelas necessidades de financiamento por parte das organizações, que buscam dessa forma acesso aos mercados internacionais de capital público e por intermediários financeiros, que por sua vez, visam oportunidades de investimento em todo o mundo.

No Brasil, o Comitê de Pronunciamentos Contábeis (CPC) foi criado pelo Conselho Federal de Contabilidade (CFC) por meio da Resolução 1.055/05 e foi de suma importância 
no processo de transição às normas do IFRS. Seus objetivos, segundo o Conselho Federal de Contabilidade (2015), é estudar, preparar e emitir Pronunciamentos Técnicos, permitindo a emissão de normas, por meio das entidades reguladoras brasileiras, objetivando a convergência da contabilidade brasileira aos padrões internacionais. Com a intenção de diminuir riscos, tanto no âmbito dos investimentos internacionais quanto dos créditos de natureza comercial, o CPC busca, para tanto, proporcionar aos investidores, financiadores e fornecedores de crédito uma melhor compreensão das demonstrações contábeis advindas de diversos países.

Carvalho (2014) coloca em destaque o papel fundamental do CPC no processo de convergência às normas internacionais garantindo assim que tal transição acontecesse de forma gradual e não de forma abrupta, atenuando assim o choque que poderia representar a adoção de um modelo internacional.

O primeiro momento da fase de transição se deu entre 2008 e 2009 com a adoção parcial do IFRS por meio da edição da Lei 11.638/07. A segunda fase, por outro lado, compreendeu a adoção obrigatória das IFRS, a partir de 2010, para as empresas brasileiras de todo o tipo de sociedade, e esse processo se mostrou necessário haja vista a necessidade de amenizar o impacto considerável que poderia ser causado diante de uma mudança expressiva de um modelo contábil local para um internacional, sendo este com uma maior complexidade e abrangência (SANTOS; PONTE; MAPURUNGA, 2014).

Para Antunes et al. (2012), a maior clareza de informação e a consequente melhor compreensão por parte dos agentes globais, proporciona redução do custo de capital. Redução esta que é buscada pelos países quando da adoção das IFRS.

No entanto, evidências empíricas indicam que os efeitos positivos da adoção das normas da IFRS, por exemplo, no custo de capital, só podem surgir se a melhoria na qualidade dos relatórios e na comparabilidade da informação é consistente com os relatos de incentivos e os mecanismos de enforcement (LOURENÇO; BRANCO, 2015a). Em outras palavras, não é claro se a obrigatoriedade das normas IFRS por si só tornam as informações financeiras mais informativas ou comparáveis (DASKE et al., 2008).

\subsection{Estudos internacionais sobre adoção das IFRS}

Alguns estudos, como o de Castillo-Merino, Menéndez-Planse e Orgaz-Guerrero (2014), analisaram os efeitos da adoção das IFRS sobre o custo de capital próprio. A partir de uma amostra de empresas espanholas listadas durante o período de 1999-2009, os autores encontraram evidências de que houve uma redução significativa no custo de capital próprio após a adoção obrigatória das IFRS em 2005. Os resultados encontrados mostraram que o aumento da divulgação de informações financeiras e a maior comparabilidade dessas informações auxiliaram na redução significativa do custo de capital.

Li (2010), nesta mesma linha, testou se adoção obrigatória às normas afetou o custo de capital próprio de países da Europa. Para tanto, o autor utilizou uma amostra de 6.456 observações, que representavam 1.084 empresas distintas, abrangendo 18 países da União Europeia, durante os anos de 1995-2006. A partir das análises, o autor encontrou evidências consistentes de que a adoção obrigatória das IFRS reduziu o custo de capital próprio das empresas europeias listadas. Porém, o autor verificou em suas análises que a obrigatoriedade do IFRS só tem impacto significativo no custo de capital apenas em países com forte poder de enforcement na aplicação das normas, sendo este um fator importante para mudanças contábeis eficazes.

Assim, como Castillo-Merino, Menéndez-Planse e Orgaz-Guerrero (2014), Li (2010) identificou dois canais por meio do qual a adoção das normas reduziu o custo de capital 
próprio: melhora na qualidade do disclosure e maior comparabilidade das informações divulgadas.

Daske et al. (2008), em outro trabalho, exploraram as consequências econômicas da adoção obrigatória das IFRS em 26 países, avaliando os efeitos na liquidez no mercado acionário, custo de capital próprio e valorização de ações utilizando regressão com dados em painel. O estudo dos autores traz várias contribuições para a literatura contábil, já que o trabalho deles foi o primeiro a analisar os efeitos no mercado de capitais em torno da introdução das novas normas para uma amostra grande e global.

Para tanto, os autores utilizaram uma amostra contemplando de 3.100 observações. Os resultados demonstraram que os adotantes obrigatórios tiveram aumento estatisticamente relevante na liquidez de mercado, redução do custo de capital e a valorização das ações das organizações. Porém, os benefícios ao mercado de capitais ocorrem apenas nos locais onde o poder de enforcement é alto e o ambiente institucional proporciona fortes incentivos às empresas serem transparentes. Os autores também demonstraram que os efeitos da adoção são mais fortes nos locais que possuem diferenças mais significativas entre o GAAP (Generally Accepted Accounting Principles) local e as IFRS, e em locais sem um plano ou estratégia prévia de convergência às normas.

Lee, Walker e Christensen (2010), assim como Li (2010) realizaram seu estudo no continente europeu. Esses, por outro lado, utilizaram uma amostra de 17 países, entre os anos de 1995-2006. A hipótese testada pelos autores é de que a adoção das IFRS reduz o capital próprio das organizações listadas nas bolsas de valores europeias. Os resultados encontrados demonstram que houve uma redução média do custo de capital próprio de $0,72 \%$ após a adoção obrigatória.

No entanto, Lee, Walker e Christensen (2010) não encontraram evidências de redução do custo de capital próprio após a redução obrigatória em empresas situadas em países onde os incentivos para o disclosure são reduzidos e também onde há baixo poder de enforcement. Fatores estes que vão de acordo com os trabalhos de Daske et al. (2008) e Li (2010).

\subsection{Estudos nacionais sobre adoção das IFRS}

A seguir são demonstrados alguns trabalhos nacionais que tratam da mesma temática do presente estudo, bem como seus resultados e conclusões. Por se tratar de um tema recente não foram encontrados na literatura especializada muitos trabalhos sobre o assunto. Mesmo dentre os encontrados, a maior parte foi retirada de anais de eventos e congressos de amplitude nacional, que são os casos dos trabalhos de Gatsios et al. (2015), Botinha e Lemes (2013), Silva e Nardi (2014), Gonçalves et al. (2015) e Silva, Pinheiro e Freitas (2014). O de Carvalho (2014), por sua vez, é sua tese de doutorado. O único artigo fruto de publicação em periódico internacional é o de Lima et al. (2010).

Gonçalves et al. (2015), por exemplo, em seu trabalho, no intuito de mensurar o impacto da convergência às Normas Internacionais de Contabilidade (IFRS) no Custo de Capital de Terceiros nas empresas brasileiras, inseriu dados obtidos de uma amostra composta por 67 empresas. O estudo contemplou dados de 43 semestres em um modelo que buscou relacionar o custo de capital de terceiros com a adoção das IFRS. Os autores identificaram que a adoção das normas internacionais ocasionou a redução no custo de capital de terceiros das empresas evidenciadas na amostra. No entanto, foram encontrados sinais contrários aos que esperavam no tocante a variáveis como taxa de endividamento (alavancagem), valor de mercado e valor dos ativos.

A pesquisa de Carvalho (2014), de forma semelhante ao trabalho de Gonçalves et al. (2015), buscou analisar, por meio das empresas de capital aberto listadas da BM\&FBovespa, 
se o custo do capital próprio foi afetado com a adesão às normais internacionais. Para tanto, adotou a seguinte classificação: a) Empresas listadas na Bolsa de Valores de São Paulo como grupo de tratamento; b) Empresas que aderiram obrigatoriamente as IFRS como grupo de controle e c) Empresas da América Latina que não adotaram as normas internacionais, como grupo de controle secundário. Por fim, o autor utilizou da metodologia de diferenças em diferenças para as análises de regressões em painel.

Os resultados encontrados não indicam que a obrigatoriedade da adoção tenha sido de forma isolada, uma condicionante que proporcionou aumento na qualidade das informações contábeis de modo a garantir uma redução no custo de capital próprio das empresas brasileiras optantes compulsórias das IFRS em 2010 (CARVALHO, 2014).

Seguindo essa linha de estudos, Silva e Nardi (2014) fizeram uso da abordagem de diferenças em diferenças para verificar os efeitos das normas nas organizações brasileiras de capital aberto no período 2000-2011 sob o custo de capital próprio. Para tanto, os autores utilizaram uma amostra de empresa que compõe a carteira teórica do IBrX-100, adicionando também outras 30 na amostra, as quais adotaram antecipadamente as IFRS. Os resultados, de forma contrária aos identificados por Carvalho (2014), apontaram para uma redução no custo de capital em torno de 7 pontos base daquelas que passaram a utilizar as normas nas demonstrações financeiras de forma compulsória. Diante do exposto, os autores apresentam evidências de que a melhora na qualidade das demonstrações financeira, a partir da adesão brasileira às normas internacionais, realmente implica na redução do custo de capital próprio.

O trabalho de Gatsios et al. (2015) segue a mesma temática dos estudos já mencionados e também utiliza a abordagem de diferenças em diferenças e regressão com dados em painel, vide Silva e Nardi (2014). Para tal, os autores fizeram uso de uma amostra de 1.325 organizações listadas na BM\&FBOVESPA, excluídas as financeiras, para o período de 2004-2013. O Modelo CAPM (Capital Asset Pricing Model), adaptado ao caso brasileiro, conhecido como CAPM por benchmark, foi utilizado para calcular o custo de capital próprio, conforme proposto por Assaf Neto et al. (2008).

A partir das análises os autores verificaram que a adoção às normas não auxiliou na redução do custo do capital próprio no Brasil. Esse resultado contrário, ainda segundo os autores, pode ser em função da fragilidade das instituições brasileiras e do poder de enforcement reduzido para cumprimento das novas normas. Ademais, citam também que pelo fato do mercado de capitais nacional ser pouco desenvolvido seja necessário um período maior para as IFRS impactarem na qualidade da informação contábil e no custo de capital próprio (GATSIOS et al., 2015).

Outro estudo que assim como Silva e Nardi (2014) fez uso da carteira teórica do IBrX100 para composição da amostra foi o de Silva, Pinheiro e Freitas (2014). Os autores usaram da análise de dados em painel com propósito de verificar a relação entre o custo de capital próprio e o nível de disclosure de 66 empresas dentro de um horizonte temporal de 6 anos (2005 - 2011). Os resultados do estudo mostram que, embora o índice de disclosure afete o custo de capital próprio das empresas em períodos anteriores à adoção das IFRS, essa realidade não se faz presente em períodos posteriores a adoção.

Já a pesquisa feita por Botinha e Lemes (2013) revelou que o nível de disclosure é negativamente correlacionado com o custo de endividamento de empresas brasileiras contempladas no índice Bovespa. Tal pesquisa que teve como objetivo estudar a relação existente entre o nível de disclosure contábil e o custo da dívida de empresas utilizou, para isso, utilizou da técnica estatística de correlação de ordem de ranqueamento de postos de spearman.

Por fim, a pesquisa de Lima et al. (2010), em suma, teve como objetivo compreender o quanto a adoção às IFRS impacta não apenas a liquidez do mercado brasileiro, como também o custo de capital próprio de uma amostra composta por 54 empresas com ações negociadas 
na BM\&FBovespa. A pesquisa se sustenta em análises estatísticas que buscam medir a influência de incentivos ao nível de empresa no que tange ao cumprimento das normas contábeis internacionais e as respectivas consequências para o mercado de capitais. Os resultados obtidos atestam que empresas maiores, mais expostas ao mercado internacional e mais necessitadas de financiamento, são, também, mais propensas a adotar práticas de IFRS. Ademais, os estudos mostraram que o custo de capital não parece estar associado com qualquer medida de convergência utilizada.

\subsection{Custo de Capital Próprio}

O tema custo de capital próprio é um tópico importante e tema de muitas pesquisas dentro da área de Finanças Corporativas. Para Pratt e Grabowski (2010), o termo pode ser definido como a taxa de retorno esperada necessária que um investidor requere para colocar fundos em um investimento de capital particular.

Muitos trabalhos já percorreram este tema, dentre eles o de Assaf Neto et al. (2008) que adaptou o modelo CAPM (Capital Asset Pricing Model) de Willian Sharpe (1964) à realidade brasileira e que representa um marco importante dentro do tema no Brasil.

O CAPM é calculado pela relação entre a covariância dos retornos de mercado e da organização e a variância dos retornos da companhia. Porém, uma vez que tal metodologia foi desenvolvida para utilização em mercados desenvolvidos, ela precisa passar por alguns ajustes quando de sua aplicação em mercados em desenvolvimento, vide o caso brasileiro (ASSAF NETO et al., 2008).

Para Assaf Neto et al. (2008), o cálculo do custo de capital próprio é aquele de maior dificuldade de determinação do Custo Médio Ponderado de Capital, ou mais conhecido como WACC (Weighted Average Cost of Capital). Tal fato ocorre devido a impossibilidade de indagar diretamente ao acionista sobre qual a taxa mínima de remuneração desejada para ele aplicar seus recursos, por exemplo, em algum investimento. Complementando essa visão, Castillo-Merino, Menéndez-Plans e Orgaz-Guerrero (2014) citam que esse fato ocorre em função dele não poder ser diretamente observável.

Assaf Neto et al. (2008) elenca em seu trabalho os principais problemas da realidade brasileira que limitam o modelo de Willian Sharpe (1964). Para melhor entendimento sugerese a leitura de tal artigo, porém dentre estes problemas cita-se, por exemplo: mercado acionário brasileiro pouco expressivo em relação ao número de companhias de capital aberto; o capital das organizações listadas é controlado por um pequeno grupo de investidores; baixa liquidez dos papéis comercializados e baixa qualidade das informações divulgadas.

Apesar de suas limitações e de críticas quanto a sua eficiência quando aplicado a determinados ambientes econômicos, o modelo do CAPM desenvolvido por Sharpe (1964), segundo Assaf Neto et al. (2008) é utilizado pela maioria dos acadêmicos e analistas de mercado brasileiro como indicativo de taxa de retorno mínima que um investidor exige em suas decisões financeiras (custo de oportunidade do capital), representando segundo os autores como quase um consenso na avaliação econômica no Brasil.

Assaf Neto et al. (2008) por fim, pondera dizendo que não identificou, dentro da literatura especializada, nenhum outro modelo disponível que satisfaça a todas as críticas.

\section{METODOLOGIA}

Utilizou-se neste trabalho como fonte de dados as demonstrações financeiras padronizadas das usinas e destilarias instaladas no Brasil. Os dados utilizados neste trabalho são nominais e foram coletados junto à base da Gazeta Mercantil, entre os anos de 1998-2006, já no restante do período, 2007-2014, os dados foram coletados junto aos websites das 
organizações e de suas respectivas publicações em Diários Oficiais. As informações, por sua vez, foram transportadas para planilhas eletrônicas onde foram tabuladas e preparadas para o uso no software GRETL (GNU Regression, Econometric and Times-Series Library).

A escolha do período de análise abrange todo o processo de convergência às normas IFRS, seja anterior à convergência, adoção parcial ou obrigatória, de forma a obter um maior número de observações temporalmente, uma vez que o número de empresas na amostra é limitado. A amostra de 16 usinas e destilarias foi composta conforme disponibilidade dos dados das organizações ao longo de todo o período supracitado, sendo este grupo formado por:

Quadro 1 - Composição da amostra

\begin{tabular}{|l|l|l|l|}
\hline Empresa & Adoção IFRS & Empresa & Adoção IFRS \\
\hline Açucareira Zillo Lorenzetti S/A & 2008 & Usina Bazan S/A & 2008 \\
\hline Álcool Azul S/A & 2013 & Usina Colombo S/A & 2008 \\
\hline Santa Cruz S/A Açúcar Álcool & 2009 & Usina Santa Adélia S/A & 2009 \\
\hline Usina Alta Mogiana S/A & 2009 & Usina Santo Antônio S/A & 2008 \\
\hline Usina Alto Alegre S/A & 2008 & Usina São Francisco S/A & 2008 \\
\hline Usina Barra Grande de Lençóis S/A & 2009 & Usina São José S/A & 2008 \\
\hline Usina Barralcool S/A & 2009 & Usina São Luiz S/A & 2009 \\
\hline Usina Batatais S/A & 2008 & Usina São Martinho S/A & 2008 \\
\hline
\end{tabular}

Fonte: Elaborado pelos autores

Dentro da amostra selecionada, somente a Usina São Martinho S/A é de capital aberto, possibilitando analisar a adoção das IFRS a partir do momento em que a organização declara em suas notas explicativas o uso do conjunto de normas IFRS e/ou CPC. Apesar da amostra ser reduzida devido a disponibilidade dos dados, as 16 organizações apresentaram uma receita total de $\mathrm{R} \$ 8,860$ bilhões no ano de 2014, o que denota certa relevância, uma vez que o setor na safra 2014/2015 movimentou cerca de R \$ 70 bilhões. Deste modo, a amostra aqui utilizada representa $12,66 \%$ do valor global para o ano.

A variável utilizada para estimar o custo de capital próprio das organizações da amostra foi construída por meio do modelo do CAPM (Capital Asset Pricing Model) de Sharpe (1964) ajustado à realidade brasileira como recomendado por Assaf Neto et al. (2008). De acordo com os autores, pelo fato da metodologia desenvolvida por Sharpe (1964) ser aplicada em mercados estáveis, o modelo precisa ser ajustado quando de sua aplicação em mercados emergentes, como o caso do Brasil.

Caso da utilização do modelo CAPM sem adaptações, sua aplicação resultaria em resultados não confiáveis. Dessa forma, o modelo sugerido de custo de capital por Assaf Neto et al. (2008) incorpora diversos ajustes de maneira a adequá-lo às características brasileiras.

Sendo assim, a equação 1 apresenta o modelo proposto por Assaf Neto et al. (2008) e aqui utilizado para o cálculo do custo de capital próprio $(\mathrm{Ke})$ das organizações.

$$
\begin{gathered}
K e_{i t}=R f(E U A)+\beta(R m(E U A)-R f(E U A))-\text { Inflação NorteAmericana } \\
+ \text { Inflação Brasileira }+ \text { Risco País do Brasil }
\end{gathered}
$$

Em que,

$K e=$ Custo do capital próprio;

$R f=$ Taxa livre de risco dos Estados Unidos;

$\beta=$ Coeficiente beta do setor;

$R m$ = Taxa de retorno de mercado dos Estados Unidos;

$(R m-R f)=$ Diferença entre o retorno de mercado e o retorno livre de risco;

Inflação Norte Americana= Inflação anual americana pelo CPI (Consumer Price Index) de cada período; 
Inflação Brasileira = Inflação anual brasileira pelo IPCA (Índice de Preços ao Consumidor Amplo) de cada período;

Risco País do Brasil = Risco país brasileiro.

O cálculo da Taxa livre de risco americana $(R f)$ foi feito pela média histórica do índice S\&P 500 da Standard \& Poors até o respectivo ano. Já a taxa de retorno de mercado dos EUA também foi calculada pela média histórica até o respectivo ano, porém pelo índice 10-year T. Bond.

Nesta mesma linha, o cálculo dos coeficientes betas $(\beta)$ das usinas e destilarias foi realizado por meio da metodologia de Assaf Neto et al. (2008), baseado nos betas desalavancados das organizações americanas obtidos na base de dados Damodaran Online. Os betas desalavancados a partir do ano de 2013 foram oriundos da classificação "Farming and Agriculture". Anteriormente a esta data, devido a inexistência desta classificação, o próprio Aswath Damodaran, após contato, sugeriu a utilização daqueles oriundos do setor "Food Processing", pois a nova classificação anteriormente estava ali inserida. Em seguida, os betas desalavancados foram alavancados pelo nível de endividamento das usinas e destilarias, aqui calculados pelo passivo dividido pelo patrimônio líquido.

Em se tratando da inflação americana, o valor utilizado em cada ano foi o do Consumer Price Index (CPI). Já no caso brasileiro, por outro lado, utilizou-se o IPCA (Índice Nacional de Preços ao Consumidor Amplo) de cada ano. Por fim, o risco país utilizado corresponde ao $E M B I+B R$ médio de cada ano, calculado pela J.P. Morgan e que, assim como o IPCA e CPI foram coletados na base de dados IPEADATA.

Para tentar explicar a variação do custo do capital próprio das empresas das usinas e destilarias da amostra, o estudo adotou 8 variáveis que, posteriormente, compõem o modelo que foi estatisticamente testado. O Quadro 2 apresenta a identidade de cálculo de cada variável do modelo aqui utilizado.

Quadro 2 - Variáveis

\begin{tabular}{|c|c|c|}
\hline Variáveis Explicativas & Sigla & Definição Operacional \\
\hline International Financial Reporting Standards & IFRS & $\begin{array}{c}\text { Variável Dummy (Adoção = 1; Não Adoção = } \\
\text { 0, a partir da declaração da empresa) }\end{array}$ \\
\hline Estrutura de Capital & END & Passivo / (Passivo+Patrimônio Líquido) \\
\hline Rentabilidade do Ativo & ROA & Lucro Operacional / Ativo \\
\hline Rentabilidade sobre o Patrimônio & ROE & Lucro Líquido / Patrimônio Líquido \\
\hline Lucratividade & LC & Lucro Líquido / Receita \\
\hline Margem Operacional & MO & Lucro Operacional / Receita \\
\hline Variáveis de Controle & Sigla & Definição Operacional \\
\hline Tamanho da Empresa & Tam & Logaritmo Natural do Ativo Total \\
\hline Variação do Crescimento & VC & $\begin{array}{c}\text { (Receita Atual - Receita do Ano Anterior) / } \\
\text { Receita do Ano Anterior }\end{array}$ \\
\hline
\end{tabular}

Fonte: Elaborado pelos autores

Como variáveis explicativas este modelo fez uso do eixo Desempenho, contemplado por quatro proxies, no intuito de avaliar o desempenho financeiro das organizações. Para tanto, além do uso do Retorno sobre o Ativo (Return on Assets - ROA) e do Retorno sobre o Patrimônio Líquido (Return on Equity - ROE), como sugerido por Castillo-Merino, Menéndez-Plans e Orgaz-Guerrero (2014), também optou-se por inserir a Margem Operacional (MO) e a Lucratividade (LC). A adição e uso destas deve-se a tentativa de explorar novas alternativas para explicar o Desempenho das usinas e destilarias. Sendo assim, espera-se que dentre as organizações da amostra aquelas com maior desempenho tenham um menor custo de capital próprio. 
A variável Endividamento, aqui calculada pela divisão do passivo pela soma do passivo somado do patrimônio Líquido, também foi utilizada como variável explicativa. Organizações com um nível maior de endividamento ou mais necessitadas de capital de terceiros têm mais estímulos para reduzir os custos de agência, o que por sua vez, poderia resultar numa menor assimetria de informações e, por consequência, em um custo de capital próprio mais reduzido. Tal variável é utilizada por autores como: Lima et al. (2010) e Carvalho (2014).

Ademais, no intuito de amenizar o impacto dos efeitos não desejáveis sobre o custo de capital próprio das empresas, o presente estudo fez uso das seguintes variáveis de controle: Tamanho da Empresa e Variação do Crescimento.

Para Espinosa e Trombetta (2007) a variável Tamanho representa uma proxy para disponibilidade de informações, e tal disponibilidade é maior para as grandes empresas do que para as menores. Dessa forma, pelo fato dessas organizações fornecerem mais informações, os ganhos futuros são percebidos pelos possíveis investidores como de menor risco, e isso implica, por consequência, em custo de capital mais baixo. Sendo assim, espera-se uma associação negativa entre o custo de capital e o tamanho da empresa, porém, esse efeito pode ser mais acentuado em mercados desenvolvidos, ponderam os autores.

Dentre a literatura especializada sobre o tema aqui citadas, vários foram os trabalhos que utilizaram a variável tamanho como controle, sejam eles nacionais ou internacionais, vide Lima et al. (2010), Carvalho (2014), Gonçalves et al. (2015), Daske et al. (2008), Li (2010), Castillo-Merino, Menéndez-Plans e Orgaz-Guerrero (2014). Por isso também da utilização dela neste trabalho. O seu cálculo, por outro lado, foi feito pelo logaritmo natural do ativo total da usinas e destilarias para cada período.

A segunda e última variável de controle utilizada é a Variação do Crescimento. Para Carvalho (2014), esta variável busca mensurar as expectativas de crescimento de uma organização. Sendo assim, àquelas com maiores oportunidades de crescimento são mais propensas a demandarem uma quantia maior de capital de terceiros, e para o autor, tal demanda, na percepção dos investidores, caracteriza essas organizações como de maior risco. $\mathrm{E}$, em função disso, espera-se que esta variável seja negativamente relacionada ao custo de capital próprio.

Por fim, adicionou-se também ao modelo a variável dummy IFRS, atribuindo dessa forma, o valor 1 a partir do ano de adoção da organização às normas na elaboração das demonstrações financeiras, conforme declarado pela mesma, e 0 anteriormente a isso.

O modelo de regressão em dados em painel foi utilizado neste trabalho a fim de verificar se o processo de convergência às IFRS impactou o custo do capital próprio das empresas do setor sucroenergético. De acordo com Gujarati (2012), em dados em painel, a mesma unidade de corte transversal é analisada ao longo de um horizonte temporal. Sendo assim, segundo o autor, os dados em painel propiciam dados mais eficientes, mais variáveis, menos colineares e com mais informação, e, além do mais, são mais adequados para observar a dinâmica da mudança. Dessa forma, o modelo aqui utilizado pode ser observado na equação 2 .

$$
\begin{gathered}
K e_{i t}=\beta_{0}+\beta_{1} I F R S_{i t}+\beta_{2} E N D_{i t}+\beta_{3} R O A_{i t}+\beta_{4} R O E_{i t}+\beta_{5} L C_{i t}+\beta_{6} M O_{i t}+\beta_{7} T \operatorname{Tm}_{i t} \\
+\beta_{8} V C_{i t}(2)
\end{gathered}
$$

Em que,

$K e=$ Custo do capital próprio;

IFRS = Dummy de adoção das IFRS;

$E N D=$ Endividamento;

$R O A=$ Rentabilidade do Ativo; 
$R O E=$ Rentabilidade do Patrimônio Líquido;

$L C=$ Lucratividade;

$M O=$ Margem Operacional;

Tam = Tamanho, dado pelo LN do Ativo;

$V C=$ Variação do Crescimento.

\section{RESULTADOS}

A Tabela 1 demonstra os valores da Média, Mediana, Moda, Variância e Valor Mínimo e Máximo das variáveis utilizadas no estudo.

Tabela 1 - Resultado da estatística descritiva

\begin{tabular}{c|c|c|c|c|c|c|c|c|c}
\hline & Ke & IFRS & END & ROA & ROE & LC & MO & Tam & VAC \\
\hline $\mathrm{N}$ & 269 & 269 & 269 & 269 & 269 & 269 & 269 & 269 & 253 \\
\hline Média & $25.60 \%$ & 0.2825 & $62.70 \%$ & $6.13 \%$ & $5.58 \%$ & $5.31 \%$ & $8.94 \%$ & 12.65 & $24.18 \%$ \\
\hline Mediana & $22.00 \%$ & 0 & $64.00 \%$ & $6.00 \%$ & $11.00 \%$ & $6.00 \%$ & $11.00 \%$ & 12.66 & $14.00 \%$ \\
\hline Moda & $21.00 \%$ & 0 & $73.00 \%$ & $8.00 \%$ & $12.00 \%$ & $4.00 \%$ & $17.00 \%$ & 11.26 & $29.00 \%$ \\
\hline Var. & $16.00 \%$ & 0.203 & $2.70 \%$ & $1.00 \%$ & $13.90 \%$ & $1.70 \%$ & $3.50 \%$ & 1.152 & $67.10 \%$ \\
\hline Mín. & $12.00 \%$ & 0 & $17.00 \%$ & $-32.00 \%$ & $-341.0 \%$ & $-46.00 \%$ & $-46.00 \%$ & 10.53 & $-90.00 \%$ \\
\hline Máx. & $139 \%$ & 1 & $98.00 \%$ & $37.00 \%$ & $69.00 \%$ & $105.0 \%$ & $200.00 \%$ & 15.54 & $9830 \%$ \\
\hline
\end{tabular}

Fonte: Elaborado pelos autores

De acordo com os resultados da estatística descritiva apresentados na Tabela 1, percebe-se que a variável "Variação do Crescimento" é a que possui maior dispersão da média, sinalizando assim para a existência de uma certa heterogeneidade entre as empresas estudadas no que diz respeito à variação do crescimento. Por outro lado, as variáveis "ROA" e a "Tamanho da Empresa" foram as que apresentaram menor variância, mostrando assim uma proximidade de valores com relação ao valor médio.

A correlação é uma medida do relacionamento linear entre variáveis. Com isso, ao analisar a correlação entre a variável "ke" (Custo do Capital Próprio) com as demais variáveis do estudo, tem-se a existência de correlação significativa (até 5\% de significância) com 7 das 8 variáveis usadas no modelo. A grande maioria apresentou relação negativa com o custo de capital. Apenas a relação entre "ke" e "Estrutura do Capital" se mostrou positiva e significante e, além disso, também apresentaram maior coeficiente de correlação comparado com as demais. A Tabela 2 apresenta os resultados da matriz de correlação entre as variáveis contempladas no estudo.

Tabela 2. Matriz de correlação

\begin{tabular}{c|c|c|c|c|c|c|c|c|c}
\hline & Ke & IFRS & END & ROA & ROE & LC & MO & Tam & VAC \\
\hline Ke & 1,00 & & & & & & & & \\
\hline IFRS & $-0,188$ & 1,00 & & & & & & & \\
\hline END & 0,5429 & $-0,0067$ & 1,00 & & & & & & \\
\hline ROA & $-0,2724$ & 0,0358 & $-0,3423$ & 1,00 & & & & & \\
\hline ROE & $-0,3136$ & $-0,0324$ & $-0,2929$ & 0,7057 & 1,00 & & & & \\
\hline LC & $-0,2763$ & 0,0735 & $-0,3282$ & 0,7369 & 0,7055 & 1,00 & & & \\
\hline MO & $-0,2507$ & 0,1731 & $-0,2176$ & 0,6961 & 0,5668 & 0,9131 & 1,00 & & \\
\hline Tam & $-0,3068$ & 0,63 & 0,0152 & 0,114 & 0,1162 & 0,2182 & 0,303 & 1,00 & \\
\hline VAC & $-0,0045$ & 0,0225 & 0,0362 & 0,0244 & 0,0394 & $-0,0283$ & $-0,0206$ & 0,0383 & 1,00 \\
\hline FO
\end{tabular}

Fonte: Elaborado pelos autores

A fim de avaliar se com a adoção das normas internacionais houve redução do custo de capital próprio das usinas e destilarias selecionadas na amostra, realizaram-se os testes de 
especificação do modelo de regressão de Mínimos Quadrados Ordinários (MQO). Ou seja, por meio da regressão em MQO foram realizados testes para verificar se o modelo apresenta especificação adequada. Os resultados dos testes estão contemplados nas Tabelas 3 e 4.

Tabela 3 - Pressupostos da Regressão

\begin{tabular}{c|c}
\hline Teste da normalidade dos resíduos & Teste de White para a heterocedasticidade \\
\hline Hipótese nula: o erro tem distribuição Normal & Hipótese nula: sem heterocedasticidade \\
\hline $\begin{array}{c}\text { Estatística de teste: Qui-quadrado }(2)=923,808 \text { com p- } \\
\text { valor }=2,49803 \mathrm{e}-201\end{array}$ & $\begin{array}{c}\text { Estatística de teste: } \mathrm{LM}=70,9144 \text { com p-valor }= \\
\mathrm{P}(\mathrm{Qui}-\mathrm{quadrado}(43)>70,9144)=0,00467413\end{array}$ \\
\hline
\end{tabular}

Fonte: Elaborado pelos autores

A Tabela 3 demonstra os resultados dos testes de normalidade dos resíduos e do teste de White para testar a heterocedasticidade do modelo. Os resultados indicam que, os resíduos do modelo não apresentam distribuição normal e, por isso, incorre no problema de heterocedasticidade. Com propósito de tornar a análise do modelo adequada, os modelos de regressão foram utilizados a partir da técnica de regressão robusta, que apresenta melhor tratamento para as especificações do modelo de regressão em situações em que não há homocedasticidade nos dados.

Tabela 4 - Teste Fatores de Inflacionamento da Variância (VIF)

\begin{tabular}{l|l}
\hline Varáveis & VIF \\
\hline Tamanho da Empresa & 1,821 \\
\hline Variação do Crescimento & 1,014 \\
\hline ROA & 2,850 \\
\hline ROE & 2,639 \\
\hline Lucratividade & 9,556 \\
\hline Margem Operacional & 7,789 \\
\hline Estrutura Capital & 1,224 \\
\hline IFRS Fonte: Elaborado pelos autores
\end{tabular}

Nota: Valor acima de 10 indicam potencial problema de multicolinearidade.

Os resultados da estatística VIF apresentados na Tabela 4 apontam para o fato de que as variáveis do modelo não podem ser consideradas multicolineares.

Os testes de LM de Breusch-Pagan, Hausman e o Teste de Chow (Tabela 5) foram feitos para verificar dentre os modelos de Efeito Fixo, Efeito Aleatório e MQO, aquele que melhor se ajusta aos dados contemplados no estudo.

Tabela 5 - Testes para escolha do modelo de Dados em Painel

\begin{tabular}{c|c|c}
\hline $\begin{array}{c}\text { Teste robusto para diferenciar } \\
\text { interceptos de grupos: }\end{array}$ & Teste de Breusch-Pagan & Teste de Hausman \\
\hline H0: modelo MQO & H0: modelo MQO \\
H1: modelo de efeitos fixos & H1: modelo de efeitos aleatórios & $\begin{array}{c}\text { H0: modelo de efeitos aleatórios } \\
\text { H1: modelo de efeitos fixos }\end{array}$ \\
\hline $\begin{array}{c}\text { Estatística de teste: } \\
\text { p-valor }=\mathrm{P}(\mathrm{F}(15,89,4)>4,59062)= \\
2,13755 \mathrm{e}-006\end{array}$ & $\begin{array}{c}\text { Estatística de teste assintótica: } \\
\text { Qui-quadrado }(1)=23,927 \text { com p- } \\
\text { valor }=1,00057 \mathrm{e}-006\end{array}$ & $\begin{array}{c}\text { Estatística de teste assintótica: Qui- } \\
\text { quadrado(8) }=55,789 \text { com p-valor } \\
=3,10071 \mathrm{e}-009\end{array}$ \\
\hline
\end{tabular}

Fonte: Elaborado pelos autores

Percebe-se que o modelo de Efeitos Fixos é o melhor ajustado para a regressão em dados em painel, uma vez que o Teste de Chow indica a preferência do modelo de Efeitos Fixos em relação ao MQO e o Teste de Hausman indica a preferência do modelo de Efeitos 
Fixos em relação ao modelo de Efeitos Aleatórios. Com isso, a análise é baseada na regressão robusta com dados em painel com modelo de Efeitos Fixos (Tabela 6).

Os resultados expostos na Tabela 6 mostram que 22,13\% da variação do custo do capital próprio pode ser explicada pelas variáveis independentes utilizadas no modelo. Não obstante, constata-se que apenas 3 das 8 variáveis independentes apresentaram significância estatística ao nível de 5\%. Faz-se importante destacar que a relação entre o tamanho da empresa e o ROE com o custo de capital próprio se mostrou negativa, ou seja, à medida que o ROE e o tamanho da empresa decrescem há um aumento no custo do capital próprio.

Tabela 6 - Modelo de Regressão de Efeitos Fixos com Erros-Padrão Robusto

\begin{tabular}{ccc}
\hline & Coeficiente & p-valor \\
\hline Ke & & \\
Const & 0,525540 & $0,0588 *$ \\
Tam & $\mathbf{- 0 , 0 4 2 6 8 2 1}$ & $\mathbf{0 , 0 1 4 8 * *}$ \\
VC & $-0,000226791$ & 0,9287 \\
ROA & 0,0464093 & 0,2358 \\
ROE & $\mathbf{- 0 , 0 3 5 4 7 7 5}$ & $\mathbf{0 , 0 3 0 3} * *$ \\
LC & 0,220412 & 0,1725 \\
MC & $-0,0878167$ & 0,2721 \\
END & $\mathbf{0 , 4 2 5 2 1 1}$ & $\mathbf{0 , 0 0 1 9 * * *}$ \\
IFRS & 0,00544719 & 0,8497 \\
\hline R-quadrado Ajustado & $22,13 \%$ & \\
\hline
\end{tabular}

Fonte: Elaborado pelos autores

É possível verificar também que a adoção das IFRS por parte das empresas não afeta estatisticamente o seu custo de capital. Tal resultado vai de encontro àqueles encontrados em Gonçalves et al. (2015), Silva e Nardi (2014), Botinha e Lemes (2013), Castillo-Merino e Menéndez-Plans e Orgaz-Guerrero (2014) e Daske et al. (2008) onde constatam que uma maior qualidade nas informações contábeis leva à diminuição do capital próprio.

Os resultados apurados na pesquisa corroboram os de Carvalho (2014), Gatsios et al. (2015), Lima et al. (2010) e Lee, Walker e Christensen (2010) na qual relatam que não houve redução do custo do capital próprio por parte das empresas que adotaram as IFRS.

O fato de adotar IFRS por parte das empresas não afetou estatisticamente o seu custo de capital. Os resultados deste trabalho contribuem para o debate acerca da qualidade da informação contábil e o possível impacto do custo de capital próprio. Entretanto, está sujeito a alguns cuidados quanto à validade externa. Primeiramente em relação à mensuração do custo de capital das empresas. Aqui, optou-se pelo modelo adaptado por Assaf Neto, por isso, quando da comparação destes resultados com de outros países imagina-se que seja necessária cautela.

Assim sendo, pode-se extrair dos resultados que a variável "Variação de Crescimento" apresenta alta dispersão da média. Além disso, a regressão mostrou que apenas três variáveis apresentaram relação significativa com o custo do capital, são elas: "ROE", "Estrutura de Capital" e "Tamanho da Empresa". Deste modo, constatou-se que a adoção do IFRS por parte das empresas não explica a variação do custo de capital. 
Quadro 3 - Síntese dos Resultados

\begin{tabular}{|c|c|c|c|c|}
\hline Variáveis & Fonte & $\begin{array}{l}\text { Resultado } \\
\text { Esperado }\end{array}$ & $\begin{array}{l}\text { Resultado } \\
\text { Encontrado }\end{array}$ & $\begin{array}{c}\text { Resultado } \\
\text { Aqui } \\
\text { Encontrado }\end{array}$ \\
\hline \multirow{2}{*}{ IFRS } & Gonçalves et al. (2015) & + & - & \multirow{2}{*}{$\begin{array}{c}\text { Não } \\
\text { Significativa }\end{array}$} \\
\hline & $\begin{array}{c}\text { Castillo-Merino e Menéndez-Plans e } \\
\text { Orgaz-Guerrero (2014) }\end{array}$ & - & - & \\
\hline \multirow{3}{*}{ Endividamento } & Gonçalves et al. (2015) & + & - & \multirow[t]{2}{*}{+} \\
\hline & Carvalho (2014) & $+/-$ & - & \\
\hline & Lima et al. (2010) & - & - & \\
\hline $\begin{array}{l}\text { Desempenho } \\
\text { (ROA e ROE) }\end{array}$ & $\begin{array}{l}\text { Castillo-Merino e Menéndez-Plans e } \\
\text { Orgaz-Guerrero (2014) - ROE }\end{array}$ & - & $\begin{array}{l}\text { Não } \\
\text { Significativa }\end{array}$ & - \\
\hline \multirow{6}{*}{$\begin{array}{l}\text { Tamanho da } \\
\text { Empresa }\end{array}$} & Daske et al. (2008) & - & $\begin{array}{l}\text { Não } \\
\text { Significativa }\end{array}$ & \multirow{6}{*}{-} \\
\hline & Li (2010) & - & - & \\
\hline & $\begin{array}{c}\text { Castillo-Merino e Menéndez-Plans e } \\
\text { Orgaz-Guerrero (2014) }\end{array}$ & - & $\begin{array}{l}\text { Não } \\
\text { Significativa }\end{array}$ & \\
\hline & Lima et al. (2010) & - & - & \\
\hline & Carvalho (2014) & - & - & \\
\hline & Gonçalves et al. (2015) & - & - & \\
\hline $\begin{array}{l}\text { Variação do } \\
\text { Crescimento }\end{array}$ & Carvalho (2014) & - & $\begin{array}{l}\text { Não } \\
\text { Significativa }\end{array}$ & $\begin{array}{c}\text { Não } \\
\text { Significativa }\end{array}$ \\
\hline
\end{tabular}

Fonte: Elaborado pelos autores

Para Espinosa e Trombetta (2007), a falta de resultados conclusivos em relação aos possíveis benefícios de um maior disclosure contábil, como redução do custo de capital, objeto de estudo deste trabalho, pode ser em parte devida às duas questões:

i) Primeiro, em relação a dificuldades de mensuração, seja em relação ao custo de capital próprio ou da qualidade do disclosure. Isso se dá em função de ambos não poderem ser diretamente observados e mensurados, o que dá margem a valores subjetivos.

ii) Em segundo lugar, em relação a questões de especificação do modelo, pois estes deixam de considerar o possível efeito de diferentes escolhas de políticas contábeis.

Ademais, Espinosa e Trombetta (2007) complementam dizendo que a interação entre a escolha das políticas contábeis e o disclosure também pode fornecer uma possível explicação dos resultados mistos obtidos até o momento em relação ao suposto efeito positivo sobre o custo de capital próprio.

Dessa forma, pode-se conjecturar que existe um maior enforcement, seja por incentivos externos de fiscalização sobre a qualidade da adoção das normas ou de benefícios obtidos pelas organizações na redução do seu custo de capital, que acaba não afetando diretamente as empresas do setor sucroenergético estudadas, uma vez que no caso brasileiro o 
enforcement maior está voltado para as sociedades anônimas de capital aberto que apresentam maior nível de fiscalização externa por auditoria e reguladores como a Comissão de Valores Mobiliários (CVM), além de apresentarem maior interesse em um melhor nível de disclosure dada a necessidade de negociação de suas ações no mercado, e esta não é a realidade da amostra.

Sendo assim, o Quadro 3 sumariza as variáveis utilizadas no modelo, incluindo as de controle, bem como os respectivos autores que também as empregaram em seus respectivos trabalhos, o resultado esperado e o encontrado em cada pesquisa

\section{CONSIDERAÇÕES FINAIS}

O presente estudo teve como propósito averiguar se com a adoção do padrão IFRS houve redução do custo de capital próprio das empresas brasileiras do setor sucroenergético. Observa-se que ao longo do período analisado, período este maior do que o utilizado nos demais trabalhos encontrados, foram contemplados diferentes cenários do setor, abrangendo desde um período de crescimento e auge até o atual cenário de crise, porém, há de se destacar a limitação do tamanho da amostra em função da disponibilidade de dados de companhias de capital fechado.

Utilizou-se do modelo de regressão com dados em painel a fim de satisfazer os propósitos da pesquisa, adotando como variável dependente o custo do capital próprio das organizações da amostra, na qual foi estimado pelo modelo CAPM (Capital Asset Pricing $M o d e l$ ) ajustado à realidade brasileira. Pelo custo de capital próprio não poder ser diretamente observável e que, de uma forma ou de outra, ele deve ser estimado, optou-se pelo modelo que se mostrou mais coerente com a realidade brasileira. Porém, cada proxie para tal pode apresentar suas vantagens e desvantagens.

A pesquisa demonstrou que um o custo de capital próprio apresenta relação negativa com as variáveis "ROE" e "Tamanho da Empresa", e positiva com "Estrutura de Capital", gerando aumento do custo do capital próprio.

Os resultados obtidos apontam, ainda, que a adoção das IFRS não afetou significativamente o custo de capital próprio das usinas e destilarias, sendo assim, eles são contrários a hipótese desta pesquisa, porém, em consonância com estudos apresentados na literatura. Tal resultado pode ser explicado em parte pelo baixo poder de enforcement no Brasil quando da aplicabilidade das normas contábeis internacionais, considerando a baixa qualidade da informação no setor, em que existe pouco interesse na divulgação frente aos benefícios da redução do custo do capital próprio, uma vez que o setor apresenta alta concentração acionária e a absoluta maioria das organizações possui capital fechado.

Portanto, os resultados sugerem que o setor sucroenergético, dada sua estrutura de governança e forma de controle acionário, não possui claros incentivos, como a redução do custo do capital próprio, para melhoria da qualidade da informação contábil a partir da adoção das IFRS.

Ressalta-se, que talvez os resultados obtidos estão sujeitos a limitações em sua análise sejam em função da metodologia utilizada para o cálculo do custo de capital próprio, e também devido a indisponibilidade de mais informações para o período de 1998-2006, conforme a base da Gazeta Mercantil. Em função disso, não foi possível fazer uso de outras variáveis de controle, tais como Volatilidade, Valor de Mercado, Auditoria Externa, Marketto-book etc. Faz-se necessário salientar, haja vista a contemporaneidade da temática estudada, que não há, por ora, em periódicos de primeira linha, trabalhos nacionais que versem sobre o tema proposto, o que podem delimitar este estudo.

Como sugestões para pesquisas futuras propõem-se novos estudos com as organizações do setor sucroenergético listadas na BM\&F BOVESPA, o uso de outras estimativas para o cálculo do custo de capital próprio e também a utilização de outras 
metodologias como a da de diferenças em diferenças utilizadas por alguns dos trabalhos aqui citados no intuito de segregar o efeito da adoção das normas internacionais sobre o custo do capital próprio.

\section{REFERÊNCIAS}

ANTUNES, M. T. P.; GRECCO, M. C. P.; FORMIGONI, H.; MENDONÇA NETO, O.R.A adoção no Brasil das normas internacionais de contabilidade IFRS: o processo e seus impactos na qualidade da informação contábil. Revista de Economia e Relações Internacionais, São Paulo, v. 10, n. 20, p.5-19, 2012.

ARMSTRONG, C. S.; BARTH, M. E.; JAGOLINZER, A. D.; RIEDL, E. J. Market Reaction to the Adoption of IFRS in Europe. The Accounting Review, v. 85, n.1, p.31-61, 2010.

ASSAF NETO, A.; LIMA, F. G.; PROCOPIO DE ARAUJO, A. M. Uma proposta metodológica para o cálculo do custo de capital no Brasil. Revista de Administração, São Paulo, v.32, n. 1, p.72-83, 2008.

BARTH, M.E.; LANDSMAN, W. R.; LANG, M. H. International accounting standards and accounting quality. Journal of Accounting Research, Chicago, v. 46, n. 3, p. 467-498, 2008.

BOTINHA, R. A.; LEMES, S. Adoção das IFRS: análise da relação do nível de disclosure com o custo de capital das empresas brasileiras. In: SEMEAD - SEMINÁRIOS EM ADMINISTRAÇÃO, 16, 2013. São Paulo. Anais... São Paulo, 2013.

BROWN, P. Some observations on research on the benefits to nations of adopting IFRS. The Japanese Accounting Review, v. 3, p. 1-19, 2013.

CARVALHO, E. M. de. Consequências econômicas da adoção compulsória das normas internacionais de contabilidade (IFRS) no custo de capital próprio das empresas brasileiras listadas na BM\&FBOVESPA. 2014. 145 f. Tese (Doutorado em Administração) - Programa de Pós-Graduação em Administração, Universidade Federal do Rio Grande do Sul, Porto Alegre, BR-RS, 2014.

CASTILLO-MERINO, D.; MENÉNDEZ-PLANS, C.; ORGAZ-GUERRERO, N. Mandatory IFRS adoption and the cost of Equity Capital. Evidence from Spanish Firms. Intangible Capital, v. 10, n. 3, p. 562-583, 2014.

CERVO, Amado Luiz; BERVIAN, Pedro Alcino; SILVA, Roberto da. Metodologia científica. 6. ed São Paulo: Prentice Hall, 2007.

CONSELHO FEDERAL DE CONTABILIDADE. Conheça o CPC. Disponível em: <http://www.cpc.org.br/CPC/CPC/Conheca-CPC>. Acesso em: 10 Out. 2015.

DASKE, H.; HAIL, L.; LEUZ, C.; VERDI, R. Mandatory IFRS Reporting around the World: Early Evidence on the Economic Consequences. Journal of Accounting Research, v. 46, n. 5, p. 1085-1142, 2008. 
ESPINOSA, M.; TROMBETTA, M. Disclosure Interactions and the Cost of Equity Capital: Evidence from the Spanish Continuous Market. Journal of Business Finance \& Accounting, v. 34, n. 9-10, p. 1371-1392, 2007.

GATSIOS, R. C.; DA SILVA, J. AMBROZINI, M. A.; ASSAF NETO, A.; LIMA, F. G. Impacto da Adoção do Padrão IFRS sobre Custo de Capital Próprio das Empresas de Capital Aberto no Brasil. In: Congresso USP de Controladoria e Contabilidade, 15, 2015, São Paulo. Anais... São Paulo, 2015.

GONÇALVES, A. A. F.; FELLET, B.G.; DENNYSE, K.; CAPOVILLA, R. A. O Impacto da Convergência às Normas Internacionais de Contabilidade (IFRS) no Custo de Capital de Terceiros nas Empresas Brasileiras: Uma Investigação Empírica. In: Congresso USP de Controladoria e Contabilidade, 15, 2015, São Paulo. Anais... São Paulo, 2015.

GUJARATI, D. N.; PORTER, D. C. Econometria Básica. 5th Ed., New York: McGraw-Hill, 2012.

IFRS. International Financial Reporting Standards. IFRS as global standards: a pocket guide. Disponível em: <http://www.ifrs.org/Use-around-the-world/Documents/IFRS-asglobal-standards-Pocket-Guide-April-2015.PDF>. Acesso em: 19 Out. 2015.

JORNALCANA. Anuário da cana 2015: safra 2014/2015. Ribeirão Preto: Procana, 2015.

LEE, E.; WALKER, M.; CHRISTENSEN, H. B. Mandating IFRS: It's Impact on the Cost of Equity Capital in Europe. Journal of International Accounting Research, v. 9, n.1, 2010.

LI, S. Does Mandatory Adoption of International Financial Reporting Standards in the European Union Reduce the Cost of Equity Capital? The Accounting Review, v. 85, n. 2, p. 607-636, 2010.

LIMA, V. S.; LIMA, G. A. S. F. de; CARVALHO, N. G. de; LIMA, I. S. Toward IFRS: Economic Consequences of Accounting Convergence In An Emerging Economy. Research in accounting in emerging economies. London: Emerald Group Publishing Limited, v. 10, p. 251-295, 2010.

LOURENÇO, I. C.; BRANCO, M. C. A Governança Corporativa e o Efeito da Adoção das IFRS: O Caso Brasileiro. Revista Universo Contábil, v. 11, n. 1, p. 157-172, 2015 a.

LOURENÇO, I. M. E. C.; BRANCO, M. E. M. de A. D. C. Principais Consequências da Adoção das IFRS: Análise da Literatura Existente e Sugestões para Investigação Futura. Revista Contabilidade \& Finanças, v. 26, n. 68, p. 126-139, 2015b.

NEVES, M. F.; TROMBIN, V. G.; KALAKI, R. B.; GERBASI, T.; RODRIGUES, J. M.; CANTO, F. T.; SIMPRINI, E. S.; ROVANHOL, P.; CONSOLI, M. H. A dimensão do setor sucroenergético: mapeamento e quantificação da safra 2013/14. 2014.

PRATT, S. P.; GRABOWSKI, R. J. Cost of Capital: Applications and Examples. 4. ed. New York: John Wiley \& Sons, 2010. 
SANTOS, E. S.; PONTE, V. M. R.; MAPURUNGA, P. V. R. Adoção Obrigatória do IFRS no Brasil (2010): Índice de Conformidade das Empresas com a Divulgação Requerida e Alguns Fatores Explicativos. Revista Contabilidade \& Finanças (Online), v. 25, p. 161-176, 2014.

SANTOS, G. R.; GARCIA, E. A.; SHIKIDA, P. F. A. A crise na produção do etanol e as interfaces com as políticas públicas. Radar: Tecnologia, Produção e Comércio Exterior, Brasília, v. 1, n. 39, p. 27-38, 2015.

SHARPE, W. F. Portfolio Theoryand Capital Markets. USA: McGraw-Hill Inc. 1970.

SILVA, L. M.; NARDI, P. C. C. A adoção completa das IFRS no Brasil reduz o custo do capital próprio? In: Congresso ANPCONT, 8, 2014, Rio de Janeiro. Anais... 2014.

SILVA, D. A.; PINHEIRO, L. E. T.; FREITAS, B. A. de. O impacto do nível de disclosure sobre o custo de capital próprio das companhias abertas brasileiras. In: Congresso Brasileiro de Custos, 21, 2014, Natal. Anais... Natal, 2014.

SOARES, M. C; RAMOS, H. R; ETCHEBARNE, M. S; GELDRES, V. (2011). Estrutura organizacional e internacionalização de empresas: um estudo de caso no Setor Sucroenergético do Brasil. Revista Ibero-Americana de Estratégia, v. 10, n. 3, p. 49-65, set./dez. 2011.

ÚNICA. União da Indústria de Cana-de-Açúcar. Produção brasileira de açúcar e de etanol. Disponível em: <http://www.unica.com.br/linhadotempo/index.html.> Acesso em: 20 Out. 2015. 